\title{
CAREO DE TESTIGOS Y PROCESADOS: SU VALOR PROBATORIO
}

\author{
María Begoña San Martín Larrinoa \\ Doctora en Derecho
}

Sumario: 1. Introducción. 2. Concepto y regulación normativa. 3. El careo como prueba: luces y sombras. 3.1. Principios probatorios. 3.2. El careo como medio probatorio. 3.2.1. Naturaleza y características. 3.2.2. Requisitos generales para la admisión del careo. 3.2.3. Influencia de los elementos subjetivos en la práctica del careo. 3.2.4. El careo en relación con otros elementos probatorios del proceso. 3.2.5. El careo y los derechos del imputado. 3.2.6. Valor probatorio del careo practicado en el Juicio Oral. 3.2.7. Valor probatorio del careo practicado como prueba anticipada. 4. Conclusiones. 5. Bibliografía.

\section{Introducción}

El presente trabajo se dirige al análisis de la institución del careo en el ámbito del proceso penal, tanto desde el punto de vista normativo como desde el doctrinal y jurisprudencial; todo ello con el objeto de examinar la incardinación de dicha práctica entre los medios de prueba utilizables en el marco penal, sus limitaciones y dificultades, pero también su alcance a efectos probatorios, mostrando, para finalizar, las conclusiones que como fruto de tal análisis hemos obtenido.

A lo largo de la realización de este estudio hemos podido constatar la escasa atención que los autores han prestado al tema que nos ocupa, que no es objeto de monografías o artículos doctrinales, sino tan sólo de escasas menciones en manuales generales de Derecho Procesal y en obras y artículos de Derecho probatorio, lo que contrasta con el abundante tratamiento que el careo ha venido teniendo en la jurisprudencia, de la cual hemos efectuado una selección lo más significativa posible, al objeto de facilitar la deseada utilidad del presente trabajo. 


\section{Concepto y regulación normativa}

Etimológicamente, «careo» significa colocar «frente a frente», «cara a cara» a dos o más personas, habitualmente con finalidad aclaratoria de sus divergencias. En el ámbito procesal penal, con la referida expresión de «careo» se denomina el enfrentamiento «cara a cara» que tiene lugar entre dos personas (aunque en ocasiones el número se incremente), para dirimir, en diálogo abierto, las contradicciones a que hayan llegado en sus respectivas declaraciones por medio de razonamientos mutuos que aclaren sus divergencias, al objeto de establecer la verdad de los hechos objeto de la causa ${ }^{1}$.

En la misma línea, la doctrina jurisprudencial define el careo como un acto procesal consistente en la confrontación de dos declaraciones (de imputados o de testigos entre sí, o de unos con otros), con la finalidad de que se descubra la verdad real o histórica².

La regulación normativa de esta práctica procesal tiene su sede principal en la Ley de Enjuiciamiento Criminal, dentro del Libro II dedicado al Sumario y, en concreto, incardinada en su Título V «De la comprobación del delito y averiguación del delincuente», Capítulo VI «Del careo de los testigos y procesados» (arts. 451 a 455), y ello por cuanto constituye un acto conexo con las declaraciones de los testigos y de los imputados. Dicha regulación lo configura como una diligencia sumarial consistente en la confrontación de las declaraciones de imputados o de testigos entre sí, o de aquéllos con éstos, que se dirige al esclarecimiento de la verdad de algún hecho o de alguna circunstancia que tenga interés para el proceso y sobre cuyo extremo las declaraciones prestadas con anterioridad por dichas personas fueren discordantes ${ }^{3}$ (art. 451 L.E.Cr.). Su práctica presupone el cumplimiento de diversos requisitos: la existencia previa de declaraciones efectuadas en la causa por las personas que van a ser sujetos del careo, que tales declaraciones sean discordantes y que el hecho o la circunstancia que se trate de esclarecer presente interés para el proceso (arts. 451 y 452 L.E.Cr.). Respecto al ámbito subjetivo, el careo debe practicarse entre dos personas, ya que aunque el texto legal permita, por excepción, que se lleve a cabo entre mayor número de ellas, sin embargo tal circunstancia puede mermar la libertad e independencia de alguno de los partícipes al verse

\footnotetext{
1 Almagro Nosete, J. y otros autores, «Derecho Procesal», Tomo II Proceso Penal, Tirant lo Blanch, Valencia, 1992, p. 294.

2 Sentencia del Tribunal Supremo de 27 de noviembre de 1993, R.A. 1993/2.768.

3 Fenech, M., El Proceso Penal, Agesa, Madrid, 1982, p. 139. Gómez Orbaneja, E. y Herce Quemada, V., Derecho Procesal Penal, Agesa, Madrid, 1987, p. 200.
} 
obligado a enfrentarse, de forma simultánea, con el testimonio colectivo de las personas que se le oponen ${ }^{4}$.

La referida diligencia sumarial, de acuerdo con los artículos 452 a 454 de la L.E.Cr., se practica a presencia judicial, leyendo el secretario a los procesados o testigos, entre quienes tenga lugar el acto, las declaraciones que hubiesen prestado y preguntando el primero, después de recordar a los testigos sus juramentos y las penas del delito de falso testimonio, si se ratifican en las mencionadas declaraciones o tienen alguna variación que efectuar. De mantenerse la discordia, el Juez hará notar cuál es ésta e «invitará a aquellos a ponerse de acuerdo», lo que supondrá la apertura de un debate de cuyos resultados, incidencias y actitudes de las partes se levantará acta.

La ley rituaria, consciente de la posibilidad de que tal acto pueda encender o acrecentar el antagonismo entre los partícipes, lo concibe como una diligencia de averiguación de carácter subsidiario ${ }^{5}$, a practicar tan sólo cuando no fuese conocido otro modo de comprobar la existencia del delito o la culpabilidad de alguno de los procesados, estableciendo además algunas posibilidades disuasorias tanto objetivas como subjetivas para la mejor búsqueda de la verdad ${ }^{6}$. Así, por una parte, y como mencionábamos anteriormente, se obliga al Juez a recordar la promesa o juramento a los testigos y las penas con las que el Código Penal castiga el delito de falso testimonio, y, por otra, el artículo 454 de la L.E.Cr. señala que el Juez no permitirá que los careados se insulten o amenacen, lo que podría producirse en el calor de las divergencias ${ }^{7}$, conduciendo, incluso, a que alguno de los partícipes modificase sus declaraciones por temor o por la tensión del momento.

La regulación normativa de la institución del careo posee otras manifestaciones en la L.E.Cr.: los artículos 713 y 729 . El primero incardinado en el Capítulo III del Título III y Libro, a su vez, Tercero de la citada Ley, dedicado al modo de practicar las pruebas durante el Juicio

4 Urquía Gómez, F. y otros autores, Ley de Enjuiciamiento Criminal. Comentarios y Jurisprudencia, Edersa, Madrid, 1990, p. 650.

5 Subsidiariedad puesta de relieve también por el Tribunal Constitucional, entre otras, S.T.C. 55/1984 de 7 de mayo; por el Tribunal Supremo SS.T.S. 11-6-83 (RA 1983/3122) y 12-11-86 (RA 1986/6937) y por la doctrina, Vid. Gómez de Liaño, F., El Proceso Penal, Forum, Oviedo, 1989, p. 137 y Navarro PÉrez, J.L., Ley de Enjuiciamiento Criminal, Comares, Granada, 1990, p. 174.

6 Montero Aroca, J. y otros autores, «Derecho Jurisdiccional III», Proceso Penal, Bosch, Barcelona, 1994, p. 211.

7 Prieto-Castro, L. y Gutiérrez de Cabiedes, E., Derecho Procesal Penal, Tecnos, Madrid, 1989, p. 206. 
Oral, concretamente al examen de los testigos. El artículo 729, por su parte, se halla incluido dentro de las disposiciones comunes a las cuatro secciones del referido Capítulo III dedicado, como hemos señalado, al modo de practicar las pruebas durante el Juicio Oral. De la mencionada regulación legal se desprende la posibilidad de realizar careos entre procesados, entre testigos o entre unos y otros, tanto de oficio como a propuesta de las partes intervinientes en el Juicio, lo que constituye una excepción al régimen general de proposición de prueba por las partes establecido en el artículo 728 de la L.E.Cr. para el procedimiento sumario, aunque se trata de una excepción que no entra en frontal colisión con el principio acusatorio porque, en cualquier caso, el órgano jurisdiccional no puede introducir en el juicio un objeto procesal diferente al formulado por la acusación, sino sólo datos fácticos que no alteren la identidad de ese objeto ${ }^{8}$.

Sin perjuicio de la regulación que sobre la práctica del careo en el juicio oral se contiene en el artículo 713 de la L.E.Cr., la doctrina jurisprudencial ha venido entendiendo que dicha práctica ha de efectuarse en el sentido que se deduce del artículo 451 de dicho cuerpo legal ${ }^{9}$ que, en consecuencia, viene a completar la regulación establecida en el artículo 713 para el plenario.

Al mencionar la legislación relativa al careo, es forzoso citar también el artículo 229-2 de la Ley Orgánica del Poder Judicial relativo a la exigencia de inmediación, presencia de las partes y publicidad para la práctica de pruebas entre las que se encuentra el careo.

\section{El careo como prueba: luces y sombras}

De la regulación normativa del careo se desprende que cabe su práctica tanto en la fase de instrucción, como durante el juicio oral, siempre que existan declaraciones de testigos o de imputados en las que se observen las discrepancias que dan lugar a su proposición u ordenación.

A fin de analizar el careo como posible medio de prueba, su alcance y su valor, resulta necesario poner de manifiesto las exigencias que

8 Vid. Ortells Ramos, M., Montero Aroca, J. y otros autores, Derecho Jurisdiccional III ..., op. cit., p. 342.

GisBERT GisBert, A., «La práctica de diligencias de prueba acordada de oficio en el juicio oral», en Revista General de Derecho, n. ${ }^{\circ} 573$, junio 1992, p. 5.141.

9 S.T.S. 10-5-89 (R.A. 1989/4.160). 
para la actividad probatoria en general se desprenden de nuestro ordenamiento jurídico ${ }^{10}$.

\subsection{Principios probatorios}

Desde la entrada en vigor de nuestra Constitución, la prueba no sólo constituye una actividad procesal regulada por las leyes de este carácter, sino que, además y sobre todo, es la manifestación del ejercicio de derechos fundamentales reconocidos en nuestro texto constitucional.

Siguiendo a Díaz Cabiale ${ }^{11}$, señalaremos que las exigencias constitucionalizadas de la actividad probatoria no hacen referencia alguna a los principios que deben presidir la misma, por lo que éstos han de deducirse de los propios derechos fundamentales que se refieren a ella, a la par que se debe acudir a las garantías procedimentales recogidas con carácter genérico en otros pasajes del texto constitucional. Así, en primer lugar, el artículo 24-2 reconoce el derecho a utilizar los medios de prueba pertinentes para la defensa ${ }^{12}$. Dicho artículo proclama, además, el derecho a la presunción de inocencia ${ }^{13}$, lo que presupone, en su aspecto cuantitativo, que ha de existir una actividad probatoria mínima ${ }^{14}$

10 Sobre la coincidencia de los principios que para la actividad probatoria en el proceso penal se desprenden de la Constitución y de la L.E.Cr.; Vid. DíAz CABIALE, J.A., «La admisión y práctica de la prueba en el proceso penal», en Cuadernos del Consejo General del Poder Judicial, 1991, pp. 22 y ss.

11 Díaz CABIAle, J.A., «La admisión y práctica...», op. cit., pp. 27 y ss.

12 Aunque el derecho a las pruebas no es, en ningún caso, un derecho a llevar a cabo una actividad probatoria ilimitada.

La relación entre el derecho a las pruebas y la indefensión marca el momento de máxima tensión de la eventual lesión del derecho (SS.T.C. 51/1985 de 10 de abril y 89/1986 de 1 de julio).

Este mismo carácter no incondicionado del derecho a producir prueba viene subrayado por la Jurisprudencia del Tribunal Europeo de Derechos Humanos, entre otras SS. 7-7-89 (Caso Bricmont), 20-11-89 (Caso Kotovski), 27-9-90 (Caso Windisch) y 19-12-90 (Caso Delta).

13 Vid. Tomás y Valiente, F., «In dubio pro reo, libre apreciación de la prueba y presunción de inocencia», en Revista Española de Derecho Constitucional, n. . 20, mayoagosto 1987, pp. 20-22.

Sobre las distintas vertientes del Derecho fundamental a la presunción de inocencia; Vid. Vegas Torres, J., «Presunción de inocencia y prueba en el Proceso Penal», La Ley, Madrid, 1993, pp. 35 y ss.

El Tribunal Europeo de Derechos Humanos mantiene, de manera preponderante, que existe infracción de la presunción de inocencia si se ha producido una declaración de un Tribunal que, sin haber sido precedida por el procedimiento legal y sin haberse respetado las garantías de la defensa, exprese un juicio de culpabilidad respecto del acusado (entre otras: Sentencia de 25-3-83 (Fundamento Jurídico 37), asunto Minelli).

14 S.T.C. $31 / 1981$ de 28 de julio. 
o más bien suficiente ${ }^{15}$. Cualitativamente significa que los medios de prueba han de ser constitucionalmente legítimos ${ }^{16}$ y poseer un signo $o$ sentido incriminador respecto a la participación del acusado en el hecho, siendo, por tanto, de cargo ${ }^{17}$, esto es, capaces de conducir al juez, mediante un razonamiento lógico, a una convicción acerca de la culpabilidad del imputado, correspondiendo la aportación de las pruebas de cargo a las partes acusadoras (entre otras, S.T.C. 70/1985 de 31 de mayo) $)^{18}$.

Como decíamos, en otros pasajes constitucionales se recogen exigencias a respetar para la realización de la actividad probatoria en el proceso penal. Así, se afirma ${ }^{19}$ que la publicidad consagrada en el artículo 120.1 de la Constitución ha de ponerse en relación con el Derecho fundamental del artículo 24.2 a un proceso público, por lo que la efectividad de tal exigencia tan sólo se cumple en el juicio oral, de acuerdo con los artículos 301, 302 y 680 de la Ley de Enjuiciamiento Criminal. En consecuencia, la actividad probatoria ha de producirse tan sólo en aquellos trámites procesales en donde la publicidad sea una exigencia. Igualmente lo ha de ser la contradicción, deducida de los derechos fundamentales plasmados en el artículo 24.1 y 2 , derecho a la tutela efectiva con proscripción de cualquier indefensión y derecho a un proceso con todas las garantías.

De la misma forma, se señala que la oralidad, a la que se refiere el artículo 120.2, implica la preponderancia del juicio oral frente a la fase instructora y, en consecuencia, la atribución de valor probatorio tan sólo a lo practicado en el juicio oral, lo que viene corroborado por el artículo 741 de la L.E.Cr. La exigencia de inmediación derivada del artículo 120 C.E. conduce al otorgamiento de valor probatorio y, en consecuencia, el acceso a la valoración judicial, tan sólo a lo practicado en

15 Entre otras S.T.C. $160 / 1988$ de 19 de septiembre.

16 S.T.C. $109 / 1986$ de 24 de septiembre.

17 SS.T.C. 174/1985 de 17 de diciembre y 150/1989 de 25 de septiembre.

18 El Tribunal Constitucional afirma, además, que la inocencia de la que habla el artículo 24 de la Constitución ha de ser entendida en el sentido de no autoría, no producción del daño o no participación en él, SS.T.C. 141/1986 de 12 de noviembre y 92/1987 de 3 de junio. También S.T.S. 27-4-94 (RA 1994/3304).

El Tribunal Europeo de Derechos Humanos incluye en el área normativa de la presunción de inocencia «el deber del Juez o Tribunal» de «ser imparcial», Casos De Cubber y Persak; Vid. JuAnes PeCes, A., «Hacia un nuevo enfoque de la presunción de inocencia. La imparcialidad del Juez como núcleo básico del derecho a la presunción de inocencia», en La Ley, 1996-1, pp. 1.756 y ss.

19 Montero Aroca, J. y otros autores, Derecho Jurisdiccional III..., op. cit., pp. 42-46.

Díaz CABIALE, J.A., «La admisión y práctica...», op. cit., p. 27. 
el juicio oral, a excepción de la prueba anticipada consistente en aquella no reproducible en el juicio oral ${ }^{20}$, que se haya practicado con observancia de las garantías necesarias para la defensa, esto es, con sujeción a las exigencias dimanantes de los principios de contradicción y de inmediación, y que se aporte en el acto de la vista en condiciones que permitan someterla a contradicción ${ }^{21}$.

Resumiendo lo anteriormente expuesto, señalamos a continuación las premisas bajo las que se ha de desarrollar la actividad probatoria dentro del proceso penal ${ }^{22}$.

a) La carga de la prueba de los hechos constitutivos de la pretensión penal corresponde, exclusivamente, a las partes acusadoras. Una prueba que ha de poseer un signo inequívocamente incriminatorio, llevada a cabo con estricta observancia de las garantías procesales y con absoluto respeto a los derechos fundamentales de la persona, que recaiga tanto sobre los elementos objetivos de la infracción de que se trate, como sobre los componentes subjetivos de la misma ${ }^{23}$.

b) La prueba ha de realizarse en el juicio oral, con estricto respeto a los principios de inmediación, oralidad, publicidad y contradicción. Como excepción se admite la denominada prueba anticipada (SS.T.C. $80 / 1986$ de 17 de junio y 137/1988 de 7 de julio) ${ }^{24}$, que se introduce en el plenario a través de la vía del artículo 730 de la L.E.Cr.

c) El órgano juzgador no puede fundamentar su sentencia en la denominada «prueba prohibida», obtenida con vulneración de derechos fundamentales, a la que se refiere el artículo 11.1 de la L.O.P.J. ${ }^{25}$.

20 Irreproducibles de forma absoluta en el juicio oral o con extrema dificultad; SS.T.C. 14 de julio de 1986 y 137/1988 de 7 de julio.

21 S.T.C. 80/1996 de 17 de junio.

22 Gimeno Sendra, V. y otros autores, «Derecho Procesal», Tomo II, Proceso Penal, Tirant lo Blanch, Valencia, 1992, pp. 79 y ss. Vid. SS.T.C. 140/1991 de 20 de junio y 103/1995 de 3 de julio.

23 Ruiz Vadillo, E., Estudios de Derecho Procesal Penal, Comares, Granada, 1995, p. 180, citando las Sentencias del Tribunal Supremo de 20 de octubre de 1988 (RA 1988/8368), 13 y 23 de diciembre de 1985 (RA 1985/6254) y (RA 1985/6447).

24 En relación con la prueba anticipada, Ruiz Vadillo señala la necesidad de una reforma procesal que acentúe la distinción entre actos de investigación y de prueba con objeto de erradicar la posibilidad de que la sentencia pueda fundamentarse en meras diligencias sumariales. A tal efecto aboga por una actualización de los supuestos de prueba anticipada (incluyendo declaraciones de testigos expuestos a coacciones, en línea con el artículo 392.1.b del C.P.P. italiano); Vid. RUIZ VADILLO, E., «La actividad probatoria en el proceso penal español», en La prueba en el proceso penal, Centro de Estudios Judiciales, Cursos, n. ${ }^{\circ}$ 12, Ministerio de Justicia, Madrid, 1993, p. 158.

25 Vid. Fernández EnTRALGO, J., «Prueba ilegítimamente obtenida», en La Ley, 1990-1, pp. $1.180 \mathrm{y} \mathrm{ss}$. 
d) Recae sobre el Tribunal sentenciador la obligación de razonar la prueba, esto es, de explicar el iter seguido para formar su convicción y llegar a la resolución que dicta (art. 120-3 C.E.). Tal deber de razonamiento se deriva no sólo de la inexistencia de prueba tasada, sino, sobre todo, del respeto a los derechos de presunción de inocencia (art. 24-2 C.E.), y tutela efectiva de los jueces y tribunales (art. 24-1 C.E.).

\subsection{El careo como medio probatorio}

Al adentrarnos en el estudio del careo como medio probatorio, es obligado poner de manifiesto la opinión que, sobre el mismo, se mantiene en el campo de la Psicología del testimonio, donde se señalan las dificultades que esta figura presenta para los sometidos a la misma ${ }^{26}$. Así, se afirma que al esfuerzo de confrontación entre lo que el testigo recuerda haber visto y lo que recuerda que ha dicho en la declaración precedente, se une el esfuerzo tendente a intuir y prevenir todo lo que la otra persona con quien es sometido a careo ha dicho o está a punto de decir en contrario. Todo ello se opone a la premisa que desde la Psicología se apunta como deseable para llevar a cabo una declaración: que se preste «con tranquilidad de ánimo, con calma, libre de toda aprensión y de preocupaciones» ${ }^{27}$.

Examinado el careo desde el punto de vista normativo y doctrinal y expuestos los principios que presiden la prueba en el proceso penal, de la que forma parte el careo, aunque a título subsidiario y dependiente de otras pruebas que contribuye a esclarecer; estamos en condiciones de adentrarnos en el estudio específico del careo como medio de prueba, un estudio que ha de dirigirse al análisis de la jurisprudencia que, emanada de órganos jurisdiccionales de diferente rango, se ha pronunciado sobre tal institución.

\subsubsection{Naturaleza y características}

Respecto a la naturaleza probatoria del careo, la mayor parte de la doctrina jurisprudencial señala que la diligencia de careo no es propiamente un medio de prueba autónomo o independiente, sino un medio de contrastar, depurar y matizar los interrogatorios de los acusados y las declaraciones de los testigos tratando de armonizarlos y de suprimir

26 Romero Coloma, A.M., «Problemática de la prueba testimonial en el proceso penal español», en Actualidad Penal n. ${ }^{\circ}$ 22, 1990, p. 239.

27 Op. cit., p. 239. 
las contradicciones existentes entre ellos o, si esto no fuera posible, contribuir, partiendo de la actitud de los careados y de la mayor o menor firmeza de sus aseveraciones y manifestaciones, a formar la convicción del juzgador o juzgadores respecto a la veracidad de tales manifestaciones en tanto en cuanto no sean coincidentes ${ }^{28}$.

Estas afirmaciones sobre la naturaleza probatoria del careo llegan incluso más lejos en algunas resoluciones, al señalar que el careo no sólo no es un medio autónomo de prueba, sino que consiste en una fórmula incidental para contrastar el contenido de declaraciones ${ }^{29}$, en un instrumento de verificabilidad ${ }^{30}$, de contraste probatorio ${ }^{31}$ o de contraste de la fiabilidad de otras pruebas ${ }^{32}$, en un instrumento de auxilio de escasa eficacia ${ }^{33}$, o en una ampliación de pruebas ya practicadas ${ }^{34}$.

Tales apreciaciones jurisprudenciales se ven ratificadas por la opinión de los autores ${ }^{35}$, entre los que incluso se ha llegado a afirmar que «no se trata de un nuevo elemento de prueba... sino... de un modo especial de practicarse (las pruebas), que si ocupa un capítulo en la Ley de Enjuiciamiento Criminal, que en esto se limita a recoger los precedentes legislativos, lo hace por necesidades metodológicas, ya que pudiendo intervenir en el careo procesados o inculpados y testigos merecería ocupar un puesto en cada uno de los capítulos dedicados a aquellos medios de prueba, (aunque) con evidente perjuicio para la economía y orden... de la Ley» ${ }^{36}$.

En esta línea se afirma ${ }^{37}$ que la mejor demostración de que el careo no tiene la naturaleza de una prueba autónoma, radica en que, según el artículo 729-1. ${ }^{\circ}$ L.E.Cr. relativo al juicio oral, es al Presidente y no al

28 SS.T.S. 12-2-86 (RA 1986/591), 16-11-87 (RA 1987/8514), 28-1-89 (RA 1989/601), 13-12-94 (RA 1994/10147), 4-11-94 (RA 1994/8399), 8-4-94 (RA 1994/2905), 26-11-93 (RA 1993/8834), 15-3-93 (RA 1993/2387), 20-2-93 (RA 1993/1382), 18-11-92 (RA 1992/9359), 7-10-86 (RA 1986/5568) y autos T.S. 20-7-94 (RA 1994/6623) y 14-9-94 (RA 1994/7336).

29 SS.T.S. 4-12-92 (RA 1992/10003), 17-6-90 (RA 1990/5323).

30 S.T.S. 20-1-92 (RA 1992/239).

31 S.T.S. 4-4-87 (RA 1987/2450).

32 S.T.S. 4-11-94 (RA 1994/8399).

33 S.T.S. 29-4-91 (RA 1991/2980).

34 SS.T.S. 27-6-89 (RA 1989/5230) y 5-2-80 (RA 1980/441).

35 Arroyo de las Heras, A. y Muñoz Cuesta, J., Ley de Enjuiciamiento Criminal, Aranzadi, Pamplona, 1993, p. 255.

36 JimÉnez AsEnjo, E. y otros autores, (Mascarenas, C.E., Dir.), Nueva Enciclopedia Jurídica, Tomo III, Seix, Barcelona, 1951, pp. 695 y ss.

37 SaAvedra Ruiz, J., «La iniciativa del Tribunal en el acto del juicio oral», en Cuestiones de Derecho Procesal Penal, Cuadernos de Derecho Judicial, C.G.P.J., Madrid, 1994, pp. 30-31. 
Tribunal a quien compete acordar los careos de oficio o a propuesta de cualquiera de las partes, a diferencia de los otros números del precepto, pues el acuerdo sobre la admisión, denegación o práctica de pruebas corresponde al órgano colegiado, de lo que se deduce que tal posibilidad del Presidente se inserta dentro de la órbita de las facultades que le corresponden en la dirección del debate.

En cuanto a las características predicables del careo en su función probatoria, según la doctrina, sustentada en este punto en la Ley de Enjuiciamiento Criminal, éstas son: la subsidiariedad ${ }^{38}$, que permite acudir al mismo cuando no haya otro medio de acreditar la existencia del delito o la culpabilidad de los procesados; y la naturaleza potestativa que ostenta, ya que compete al órgano judicial, de modo discrecional ${ }^{39}$, acordar su práctica o denegarla, si bien de forma razonada ${ }^{40}$, sin que la negativa constituya vulneración del artículo 24-2 de la Constitución Española: derecho a utilizar los medios de prueba pertinentes para la defensa, dado el carácter potestativo y subsidiario de dicha prueba (S.T.C. 55/1984 de 7 de mayo). Esta discrecionalidad conduce a que la decisión que se adopte por el tribunal a quo, conforme declaración sempiterna e invariable del Tribunal Supremo, no sea revisable en Casación ${ }^{41}$.

Igualmente, constituye otra de sus características fundamentales la de ser consustancial a la práctica de la misma la inmediación, lo cual se desprende no sólo del requerimiento que en este sentido impone la naturaleza de este peculiar medio de prueba, sino también del propio ar-

38 Subsidiariedad predicable también del careo en el ámbito de la Justicia Militar, lo que se desprende de los artículos 616 a 619, 741-5 y 753 del Código de Justicia Militar (S.T.S. Sala 2. ${ }^{\text {de }}$ 22-4-83 (RA 1983/2300).

39 Según la jurisprudencia, la denegación del careo en el juicio oral, conforme posibilita el artículo 729-1 de la L.E.Cr., no constituye un acto de discrecionalidad pura, sino el ejercicio de facultades discrecionales jurídicamente vinculadas. SS.T.S. 8-2-91 (RA 1991/916) y 12-12-91 (RA 1991/9143).

40 Aunque se admite que tal razonamiento pueda ser escueto S.T.S. 26-11-93 (RA 1993/8834).

41 SS.T.S. de 4-12-92 (RA 1992/10003), 19-1-93 (RA 1993/396), 26-11-93 (RA 1993/8834), 4-11-94 (RA 1994/8399), 26-11-90 (RA 1990/9860), 17-6-90 (RA 1990/5323).

Aunque ello no sea obstáculo, según el alto Tribunal, para que, dado el derecho constitucional a la utilización de los medios de prueba pertinentes, relacionado íntimamente con el también derecho fundamental a no sufrir indefensión, en casos excepcionales en que, efectivamente, quede acreditada la pertinencia de dicha prueba por darse los presupuestos de los artículos 451 y 452 L.E.Cr. y existir datos que hagan presumir que el careo ofrecería resultados positivos para el enjuiciamiento, pueda provocar indefensión la denegación no motivada de tal prueba, S.T.S. 13-12-94 (R.A. 1994/2.162). 
tículo 453 de la L.E.Cr. que prevé como circunstancia a reseñar de la práctica del careo la actitud que muestren sus partícipes en el desarrollo del mismo.

El análisis jurisprudencial que realizamos sobre la naturaleza y características del careo en el ámbito probatorio del proceso penal no estaría completo si no nos refiriésemos a unas circunstancias que hunden sus raíces en el propio texto de la Ley de Enjuiciamiento Criminal, artículo 454, y que tienen un reflejo sistemático en la doctrina del Tribunal Supremo: la reticencia hacia la práctica del careo debido al riesgo de enfrentamientos entre los intervinientes en el mismo, «generalmente llevado a cabo bajo la pasión cuando no bajo la violencia» ${ }^{42}$; y su discutible utilidad, «ya que raras veces conduce a resultados positivos» ${ }^{43}$. De ahí que su pertinencia se supedite al criterio potestativo del órgano judicial, atribuyéndosele un carácter subsidiario respecto a otras pruebas $^{44}$.

La proclividad del careo a producir enfrentamientos verbales o incluso físicos entre los intervinientes, con resultados muy discutibles por la frecuente irreductibilidad de las posiciones que se mantienen y por producir, generalmente, más confusión que claridad ${ }^{45}$, es la clave de bóveda en la que se apoya toda la estructura de la admisión y práctica judicial de tan peculiar medio probatorio y la valoración que, con posterioridad, se efectúa del mismo, como tendremos ocasión de comprobar por los diferentes supuestos jurisprudenciales que, a título ilustrativo, pasamos a reseñar.

\subsubsection{Requisitos generales para la admisión del careo}

La doctrina jurisprudencial ha puesto de manifiesto reiteradamente $\mathrm{e}^{46}$ los requisitos básicos que han de cumplirse al solicitar la práctica del careo como medio probatorio. Así, señala que para la viabilidad del

42 S.T.S. 28-11-91 (RA 1991/9448).

43 S.T.S. 31-1-89 (RA 1989/636).

44 Ambas circunstancias, la de la prevención mostrada por la jurisprudencia y la concepción legal del careo como residual son criticadas por Ramos Méndez, quien afirma que ambas posiciones deben ser revisadas a fondo, señalando que «las reticencias en torno a la figura no tienen fundamento alguno y debe otorgársele el mismo rango que a cualquier otra actividad... en los casos en que (sea) útil la figura», vid. RAMOS MÉNDEZ, F., El proceso penal. Segunda lectura constitucional, Bosch, Barcelona, 1991, p. 217.

45 S.T.S. 14-1-93 (RA 1993/161).

46 SS.T.S. 18-4-81 (RA 1981/1451), 30-10-81 (RA 1981/4227), 17-1-81 (RA 1981/145) y 25-2-82 (1982/678). 
mismo es preciso que se proponga en momento procesal oportuno $47 \mathrm{y}$ con las formalidades legales; que la prueba sea pertinente en un doble aspecto, objetivo, en cuanto que ha de estar relacionada con la materia del proceso, y funcional, en el sentido de que ha de dirigirse al conocimiento y esclarecimiento del mismo ${ }^{48}$.

También se requiere dar a conocer el contenido del careo que se pretende al objeto de que se pueda determinar por el órgano judicial la pertinencia y necesidad de su práctica.

\subsubsection{Influencia de los elementos subjetivos en la práctica del careo}

Dadas las especiales características del careo, que puede colocar frente a frente, precisamente, a delincuente y víctima, la jurisprudencia se ha venido mostrando reticente a su admisión en aquellas ocasiones en las que ha apreciado una gran disparidad de edad o madurez entre ambos partícipes o ha percibido la posibilidad de que la práctica de tal prueba causase un daño sobreañadido a la víctima, propiciando una auténtica victimización secundaria.

Así, en una causa por violación ${ }^{49}$, el Tribunal a quo denegó la práctica de la prueba de careo en el juicio oral, «... en atención a la situación en que se encontraba la perjudicada en el acto del juicio...».

En otro supuesto, referido también a un delito contra la libertad sexual $^{50}$, el Tribunal Supremo ensalza la razonabilidad del acuerdo del Tribunal de instancia al desestimar la petición de celebración de careo entre un mayor de edad y un niño, señalando el alto Tribunal que «la confrontación del testimonio (de un niño) con un adulto, sobre no ser en principio relevante (como por lo demás una larga experiencia judicial revela que casi nunca lo es la diligencia de careo), puede ocasionar graves daños en el siquismo de una persona en formación...».

En esta misma línea es de destacar una Sentencia del Tribunal Supremo $^{51}$ referida también a un delito contra la libertad sexual realizado

47 La S.T.S. de 23-10-87 (RA 1987/7587) rechaza el recurso de casación por quebrantamiento de forma alegando denegación de careo, ya que «la Ley de Enjuiciamiento Criminal no impone al Juez la celebración de careo cuando las partes lo propongan... la propuesta se hizo extemporáneamente cuando se reanuda el juicio, tras su suspensión...».

48 En la S.T.S. de 2-3-92 (RA 1992/1670) se señala que «la diligencia de careo pedida en el acto de celebración del juicio plenario ... era absolutamente intrascendente para acreditar el hecho delictivo en sí y la identificación del culpable, al aparecer expuestos tales extremos en las diferentes declaraciones y reconocimientos del procesado hechos por la perjudicada...».

49 S.T.S. $31-1-89$ (RA 1989/636).

50 S.T.S. 26-5-92 (RA 1992/4492).

51 S.T.S. 12-2-86 (RA 1986/591). 
contra menores, en la que, a pesar de haber sido solicitada la prueba de careo por la defensa en el escrito de calificación provisional, y declarada pertinente, una vez abiertas las sesiones del juicio oral, practicado el interrogatorio del procesado y la prueba testifical, se denegó el careo, señalando el Tribunal que la denegación del juzgador $a$ quo «... fue plausible y es compartida por este Tribunal... porque habiendo prestado, las ofendidas, sus declaraciones dentro de las solemnidades del juicio oral y habiendo sido interrogadas por el Ministerio Fiscal y repreguntadas por la defensa del acusado, todo ello en presencia de éste, era innecesario el careo mencionado, siempre violento y poco esclarecedor al ser menores las que habían de carearse con el imputado, $y$, finalmente, porque tratándose de delitos de abusos deshonestos estuprosos o de prevalimiento, la superioridad de que se valió el procesado para la consumación de sus libidinosos propósitos, superioridad que dimanó de su condición docente, frente a las que fueron sus alumnas, se hubiera manifestado también durante la práctica de los careos, sobrecogiendo a las ofendidas, presas del mismo metus reverentialis que determinó su sumisión a los deseos lascivos del imputado».

También en torno a esta filosofía giran los razonamientos de otra Sentencia del Tribunal Supremo ${ }^{52}$ que, en un supuesto de violaciones reiteradas de un padre respecto a su hija de 12 años, apoya la negativa de la Audiencia a la práctica del careo manifestando en su sentencia que «ha de ponerse de relieve, y a cualquiera se le ocurre, que, indudablemente, se resolvió así con acierto a la vista de la notoria inferioridad psicológica de la hija respecto de su padre y del daño moral que tal diligencia en esas circunstancias podía haber producido en la niña...».

De la misma forma, en un supuesto de agresión sexual a una niña de 14 años con una edad mental de 7 a 10 años, en el que el Tribunal de instancia denegó la práctica de un careo, el Tribunal Supremo ${ }^{53}$ manifiesta que «una muchacha en las circunstancias psíquicas que refleja la sentencia, situada en un careo frente a sus agresores reales o potenciales, a nada o muy poco podía conducir, puesto que en el acto mismo del juicio oral, en la misma sesión, fueron vistas y oídas las declaraciones de aquéllos y de ésta y el Tribunal pudo perfectamente valorarlas apreciando sus respectivas credibilidades».

52 S.T.S. 29-4-91 (RA 1991/2980).

53 S.T.S. 26-11-91 (RA 1991/8562). 


\subsubsection{El careo en relación con otros elementos probatorios del proceso}

La doctrina jurisprudencial pone de manifiesto la aplicación estricta del principio de subsidiariedad de la prueba de careo, denegando ésta cuando los demás elementos probatorios sean suficientes para adoptar la resolución judicial.

Frente a recursos de casación basados, bien en la violación de derechos fundamentales o en quebrantamiento de forma por denegación de la prueba de careo por el Tribunal a quo, el Tribunal Supremo, además de hacer hincapié en el carácter discrecional de la práctica del careo, en cuanto que es potestativa del juez, afirma reiteradamente su subsidiariedad respecto de otras pruebas. Así, en Sentencia de 16-3-87 (RA $1987 / 2170$ ) se afirma que «... en plenario (existían) pruebas documentales y periciales —objetivas en suma - que (acreditaban) sobradamente la confabulación de ambos procesados para la comisión del delito de falsificación.... Las terminantes pruebas que le incriminan... hacían innecesaria la diligencia de careo, tanto en la fase sumarial como en el juicio oral...; por lo que... la Sala de instancia dispuso de un material probatorio más que suficiente para deducir la culpabilidad de los procesados...». Del mismo modo, en otra sentencia que resuelve un recurso de casación fundado en la denegación de la práctica de un careo por el Tribunal de instancia, señala que «... en el caso de autos el Tribunal $a$ quo dispuso de prueba dimanante no sólo de las declaraciones de los procesados, sino testifical, en especial de la víctima del delito e incluso documental y pericial, que le permitían sentar criterio fundado para admitir o no la práctica del careo referido en el acto del juicio oral ${ }^{54}$. Igualmente, en un supuesto de tenencia ilícita de armas, el alto Tribunal señala que «...el examen de la causa... pone de relieve que el extremo ... objeto de esclarecimiento — pertenencia del arma ocupada al recurrente- estaba suficientemente demostrado, por lo que... el criterio del juzgador de la negación es acertado y no produce indefensión ${ }^{55}$. Esta doctrina se reitera de nuevo por el alto Tribunal ${ }^{56}$ al afirmarse en otra resolución que «...es inconcuso que los jueces de instancia tuvieron sobrados elementos de juicio para establecer cuáles eran los hechos que resultaban probados y cuál la calificación jurídica que correspondía a los mismos, sin que, por tanto, ninguna de las pruebas que se dicen injustamente denegadas hubiera incidido en modo alguno en sus

\footnotetext{
54 S.T.S. 26-11-90 (RA 1990/9860).

55 S.T.S. 25-2-82 (RA 1982/678).

56 S.T.S. 13-3-92 (RA 1992/2091).
} 
conciencias a la hora de proferir el fallo reclamado, por lo que, por ello y porque además las pruebas a practicar en el acto del juicio plenario son las señaladas en los artículos 688 a 731 de la Ley Procesal Penal, y no otras, entre las que las de careo lo serán sólo si el Presidente las acuerda ${ }^{57}$, procede desestimar los relatados motivos...».

Respecto a la doctrina jurisprudencial anterior, es de destacar que autores como Moreno Catena ${ }^{58}$ se muestran contrarios a la discrecionalidad de los tribunales que con tanta insistencia se reitera respecto al careo. Así, afirma el referido procesalista, «el derecho a la prueba incluye el careo como una más, sin consideraciones de oportunidad y mucho menos derivadas de una prevención contra un resultado vano o el riesgo de insultos..., por lo que ha de desterrarse la discrecionalidad en su otorgamiento». Como se puede apreciar, esta concepción del careo parte de su consideración como medio de prueba, extremo éste que resulta negado por la mayor parte de la jurisprudencia que no lo concibe como un medio de prueba autónomo e independiente, sino como un medio de contrastar, depurar y matizar las declaraciones de los testigos o, en su caso, de éstos y de los imputados; de ahí que se otorgue carácter excepcional a su práctica en juicio y se condicione su admisión a decisiones discrecionales, aunque motivadas, no pudiendo realizarse su revisión en casación.

\subsubsection{El careo y los derechos del imputado}

Una de las características del careo, que con anterioridad hemos puesto de manifiesto y que se desprende tanto de la legislación adjetiva (arts. 454 y 455 L.E.Cr.) como de la propia doctrina jurisprudencial, es la proclividad de éste para producir enfrentamientos e incluso violencias, al menos verbales, como consecuencia del encuentro que se lleva a cabo entre sus partícipes, frecuentemente antagonistas a consecuencia del delito objeto de la causa. La delicada situación que se crea con el careo tiene como objetivo último, según manifiesta el artículo 713 de la Ley de Enjuiciamiento Criminal referido a su práctica en el plenario, «llegar a descubrir la verdad». Tal objetivo y la situación de enfrentamiento que frecuentemente provoca, pueden producir fuertes y encontra-

57 Además, la Circular de la Fiscalía del Tribunal Supremo de 15 de septiembre de 1883, dispone que al presidente del tribunal le está reservada la dirección de los careos en todos los casos y sólo con su venia podrán entenderse directamente las partes con los testigos... y procesados en sus respectivos casos; Vid. VALLE MuÑIz, J.M., Ley de Enjuiciamiento Criminal y otras normas procesales, Aranzadi, Pamplona, 1995, p. 143.

58 Moreno Catena, V. y otros, Derecho Procesal Penal, Colex, Madrid, 1996, p. 416. 
das reacciones entre los intervinientes, lo cual, cuando de los mismos forma parte el imputado, se compagina mal con la imposibilidad de ser obligado a declarar (art. 17-3 C.E.) y con los derechos que ostenta a guardar silencio, a no declarar contra sí mismo y a no confesarse culpable (arts. 520 L.E.Cr. y 24-2 C.E. ${ }^{59}$, y difícilmente armoniza con el propio Derecho natural, ya que la situación de enfrentamiento y de tensión que el careo frecuentemente genera merma la libertad del imputado. Este no tiene obligación de colaborar para que la justicia le castigue ni puede ser compelido, ni aún de forma indirecta, a declarar la verdad en su propio daño ${ }^{60}$, cuando, además, tal declaración puede ser determinante de una sentencia de culpabilidad.

Como consecuencia de la reflexión anterior, se podría, incluso, manifestar cierta duda respecto a la constitucionalidad de la prueba de careo ya que, a pesar de que el encausado pueda ser advertido, con carácter previo a su realización, de los derechos que le asisten, sin embargo, la tensión y el enfrentamiento que puede llegar a producir dicha prueba pueden afectar de tal forma al imputado que se violente, en la práctica, su derecho al silencio, a no confesarse culpable, a no declarar contra sí mismo $^{61} \mathrm{y}$, en conclusión, a su defensa ${ }^{62}$. Por otro lado, el sometimiento del imputado a tal situación resulta contrario a los principios de respeto a la dignidad humana que presiden nuestra Constitución y la Ley de Enjuiciamiento Criminal y del que es un ejemplo el artículo 393 L.E.Cr. que exige el mantenimiento de la serenidad de juicio en las de-

59 Incluso con el derecho a mentir, que como consecuencia de los derechos a no declarar contra sí mismo y a no confesarse culpable ostenta, Vid. RuIZ-JARABo Colomer, D., «El derecho del inculpado a no declarar y a no decir la verdad», en Poder Judicial, n. ${ }^{\circ}$ 6, marzo 1983, p. 27.

Vázquez Sotelo reconoce la existencia de tal derecho a mentir a partir de la Constitución, «como un derecho político-cívico reconocido en un supremo homenaje a la libertad individual aún a costa de la moralización del proceso penal y de la ética y probidad que debe observarse en los comportamientos procesales», Vid. VÁzQuez Sotelo, J.L., Presunción de inocencia del imputado e íntima convicción del Tribunal, Bosch, Barcelona, 1984, p. 101.

60 VÁzquez Sotelo, J.L., Presunción de inocencia ..., op. cit., p. 95.

Almagro Nosete, J., Constitución y proceso, Bosch, Barcelona, 1984, pp. 111.

61 Queralt Jiménez pone de manifiesto cómo «... los derechos fundamentales se hallan en tensión en el proceso penal...»; Vid. QueRALT JiMÉnEZ, J.J., «Instrucción y Derechos Fundamentales. A propósito del Procedimiento Abreviado», Actualidad Penal, n. ${ }^{\circ}$ 40, 30 octubre-5 noviembre 1995, p. 767.

62 Como afirma Stampa Braun «el que la persona pueda defenderse libremente... (es un) derecho fundamental en cualquier sociedad desarrollada, que es tanto como decir en cualquier sociedad que haya alcanzado plena realización jurídica»; Vid. STAMPA BRAUN, J.M., «Los derechos de la defensa y los límites de su ejercicio», en Poder Judicial, n. ${ }^{\circ}$ 14, marzo 1985, p. 24. 
claraciones de los procesados, concediéndoles el tiempo necesario para descansar y recuperar la calma.

Como afirma Vázquez Sotelo ${ }^{63}$ «De lo que se trata, en definitiva, es de que la libertad sea compatible con la autoridad en el proceso penal moderno y para ello es necesario que el encausado siga siendo "sujeto" -y además... presumido inocente y no se le rebaje a la pura condición de objeto». La eficacia del Estado no se ha de obtener a costa de la libertad y dignidad de la persona sometida al enjuiciamiento criminal.

\subsubsection{Valor probatorio del careo practicado en el juicio oral}

Partiendo de las premisas de que en el proceso penal no hay pruebas tasadas que obliguen a dar por acreditado un hecho con una sola de aquéllas y que el derecho a la presunción de inocencia, consagrado en el artículo 24.2 de la Constitución, se asienta sobre la libre valoración de la prueba por el juzgador de instancia, acorde con el ejercicio de la potestad jurisdiccional que el artículo 117-3 C.E. le atribuye ${ }^{64}$; señalaremos que la presunción de inocencia requiere para su enervación una actividad probatoria de cargo que evidencie tanto la existencia del hecho punible como la participación que en ella tuvo el acusado. En consecuencia, resulta claro que el valor probatorio del careo está unido, indisolublemente, a la apreciación, que en cada caso concreto y en conciencia (art. 741 L.E.Cr.) ${ }^{65}$, efectúe el juzgador a quo; una apreciación en la que, indudablemente, el careo será puesto en relación con los demás medios probatorios, de forma que sean «ponderados libremente por el juzgador, a quien corresponde valorar su

63 VÁzQuez Sotelo, J.L., Presunción de inocencia..., op. cit., p. 107.

${ }^{64} \mathrm{La}$ doctrina constitucional ha ido perfilando progresivamente este principio general a través de varias etapas, siendo las principales: a) Control constitucional de la existencia misma de actividad probatoria (S.T.C. 31/1981 de 28 de julio); b) Control de la explicitación del razonamiento o de la motivación de la resolución judicial (SS.T.C. 150/1988 de 15 de julio, 196/1988 de 24 de octubre y 150/1989 de 25 de septiembre); c) Revisión limitada de los hechos o valoración constitucional fáctica (SS.T.C. 229/1988 de 1 de diciembre, 107/1989 de 8 de junio); d) Revisión de la fundamentación jurídica o interpretación legal (SS.T.C. 175/1989 de 30 de octubre; Vid. Gui Mori, T. «Filosofía constitucional de la prueba», en La Ley, 1991-2, p. 1152.

65 El Tribunal Supremo en su Sentencia de 15-12-81 (RA 1981/5009) afirma que la expresión «según su conciencia» significa que la fijación de los hechos probados la hará el juzgador ateniéndose a las reglas del criterio racional.

Vid. FERnÁndez EnTRALGo, J., «Presunción de inocencia, apreciación de la prueba y motivación de la sentencia», en Revista General de Derecho, n. ${ }^{\circ} 493-494$, octubre-noviembre 1985 , p. 3141. 
significado y trascendencia en orden a la fundamentación del fallo y contenido de la sentencia» ${ }^{66}$.

A pesar de la variabilidad que tales parámetros pueden imprimir al valor probatorio del careo, sin embargo, del examen realizado sobre la jurisprudencia que se pronuncia acerca del mismo se desprenden algunos de los criterios que poseen los órganos judiciales en la tarea valorativa del careo.

Así, el análisis jurisprudencial realizado pone de manifiesto que las características del careo como medio de prueba carente de autonomía y de independencia respecto a las pruebas personales que contrasta, depura o matiza; su otorgamiento potestativo por parte del juzgador a quo, sin sujeción a revisión casacional; su carácter subsidiario respecto a la práctica de otras pruebas, dimanante del artículo 455 de la L.E.Cr. ${ }^{67}$; la concepción peyorativa existente sobre el mismo, al que incluso se le tilda jurisprudencialmente de «sedicente medio probatorio» ${ }^{68}$ y el decisivo papel de la inmediación en la práctica de tal prueba, han conducido a que la jurisprudencia haya venido afirmando que «...la valoración de esta prueba, más aún que ninguna otra, esta reservada a la libre, íntima y racional apreciación del juzgador, conforme al artículo 741 de la L.E.Cr....» ya que con el careo «más que investigar sobre hechos acaecidos, se está operando sobre un presente (actitud durante el acto), aunque sea con finalidad de descubrir la posible ocurrencia de aquellos» ${ }^{69}$.

Tomando ejemplos jurisprudenciales de los que se desprende el valor probatorio otorgado al careo en los diferentes supuestos, destaca en los mismos, además de la complementariedad con que se concibe dicha prueba respecto a declaraciones de imputados o de testigos, la importancia que los juzgadores conceden a las actitudes de las partes durante el desarrollo del propio careo.

Así, respecto a la complementariedad de tales pruebas, hay que partir de la base de que es doctrina establecida por el Tribunal Constitucional y por el Tribunal Supremo, sobre todo en delitos en los que normalmente es muy difícil la presencia de otras personas durante la

66 Vid. S.T.C. 31/1981 de 28 de julio y comentarios a la misma de AlbaCAR, J.L., «El principio de libre apreciación de la prueba en la doctrina del Tribunal Constitucional», en La Ley, 1981-4, pp. 1086 y ss. y CóRDOBA RoDA, J., «El Derecho a la presunción de inocencia y la apreciación judicial de la prueba», en Revista Jurídica de Catalunya, n. ${ }^{\circ}$, 1982 , pp. 817 y ss.

67 S.T.S. 4-5-95 (RA 1995/3558).

68 Entre otras, SS.T.S. 7-10-86 (RA 1986/5568) y 8-6-94 (RA 1994/4546).

69 S.T.S. 7-10-86 (RA 1986/5568). 
comisión de los hechos ${ }^{70}$, que «el testimonio de la víctima de un delito tiene aptitud y suficiencia para enervar el principio de presunción de inocencia siempre y cuando no existan razones objetivas que invaliden sus afirmaciones o provoquen dudas en el Juzgador y le impidan formar su convicción, incluido el aspecto de credibilidad cuya valoración corresponde al Tribunal de instancia» ${ }^{71}$. En consecuencia, se considera jurisprudencialmente que el careo practicado con tales precedentes puede contribuir a remarcar las declaraciones efectuadas con anterioridad y reafirmar la prueba. Así, se señala que «el contraste de las (imputaciones) efectuado en el Plenario bajo los principios de oralidad, contradicción e inmediación arroja un saldo positivo en favor de las afirmaciones acusatorias, las cuales en dicho trámite se consolidaron después de practicarse un careo con el procesado... $\gg^{72}$. En esta misma línea la Sentencia del Tribunal Supremo de 2-3-94 (RA 1994/2095), referida a un delito contra la salud pública, señala que «... las declaraciones de las hermanas... y los careos efectuados entre todos los implicados en este asunto... bastan y sobran, como pruebas de signo incriminatorio que son, para enervar el referido principio dejándolo inane y sin valor alguno...».

En cuanto a la importancia que los órganos judiciales conceden, a efectos de prueba, a las actitudes mostradas por las partes durante el careo, se puede mencionar, a título de ejemplo, una sentencia referida a un caso de violación en la que se afirma que el «careo con el acusado en el acto del Juicio Oral, (se evaluó) por la Sala con la inmediación que proporciona su presencia física y deposición personal, ... sin apreciar signos de contradicción o actitudes de resentimiento o enemis$\operatorname{tad} \ldots \gg^{73}$. Del mismo modo, en otra Sentencia del Tribunal Supremo de 12-7-90 (RA 1990/6304) se pone de manifiesto la apreciación que del careo había realizado el juzgador a quo, señalando que en el acto del juicio oral la víctima recordó los hechos al procesado «con gran firmeza». Igualmente, en otra Sentencia, esta vez de la Audiencia Provincial de Cuenca, de 24 de febrero de 1993, se hace hincapié en la actitud de los intervinientes en el careo, al señalar que observo «igual firmeza en ambas careadas».

70 S.T.C. 229/1991 de 28 de noviembre y SS.T.S. 12-7-90 (RA 1990/6304) y 24-11-89 (RA 1989/8721).

71 SS.T.S. 5-3-94 (RA 1994/6605), 14-5-94 (RA 1994/3700), 22-3-95 (RA 1995/4562), 2-1-96 (RA 1996/78).

72 S.T.S. 2-1-96 (RA 1996/78); destaca en este caso la circunstancia de que la víctima era deficiente mental.

73 S.T.S. 2-1-96 (RA 1996/78). 


\subsubsection{Valor probatorio del careo practicado como prueba anticipada}

Normativa y jurisprudencialmente se afirma que los únicos medios de prueba válidos para desvirtuar la presunción de inocencia son los practicados en el juicio oral (en condiciones de igualdad entre acusador y acusado y con respeto a los principios de inmediación, contradicción, oralidad y publicidad). Ahora bien, es necesario señalar que en la fase de instrucción se pueden practicar auténticas pruebas que son la excepción a la práctica de éstas en el juicio oral. Se trata de pruebas anticipadas, estrictamente excepcionales, que no pueden ampliar su operatividad más alla de su propia justificación ${ }^{74}$.

La realización de prueba anticipada está sujeta a varios requisitos ${ }^{75}$. El primero, en consonancia con lo dispuesto en el artículo 448 de la L.E.Cr., consiste en su imposible reproducción en el juicio oral (imposibilidad absoluta o extrema dificultad, según la doctrina constitucional ${ }^{76}$ ) y la previsibilidad de ésta, lo que conlleva la adopción de una resolución formal por parte del Juez instructor, a fin de posibilitar la práctica de la prueba anticipada con todas las garantías. Así se podrán practicar pruebas testificales e incluso realizar los careos que, al respecto, se estimen necesarios.

El segundo requisito a cumplir para la práctica de prueba anticipada consiste en que ésta se lleve a cabo con contradicción - o, al menos, con posibilidad de la misma-e inmediación judicial real ${ }^{77}$.

Finalmente, el tercer requisito para realizar prueba anticipada consiste en someterla, en el mismo acto del juicio, a la necesaria contradicción, lográndose con la lectura de las actas de las declaraciones o careos llevados a cabo en la fase de instrucción.

De lo anteriormente referido se desprende que la prueba anticipada, que se haya llevado a cabo con las referidas garantías y haya sido objeto de contradicción en el juicio oral, adquiere un valor de prueba plena y es susceptible de desvirtuar la presunción de inocencia de que goza el imputado, lo que resultaría predicable, igualmente, del careo practicado en las situaciones y con las garantías que se han dejado expuestas. Sin

74 Vid. GARCÍA GARcía, J., «La fase de instrucción en diligencias de carácter criminal», en La Ley, 1994-2, p. 1058.

75 TAFUR LÓPEZ DE LEMUS, J., «Valor probatorio de las declaraciones de testigo no presente en el acto del juicio oral», en Actualidad Penal, n. ${ }^{\circ}$ 18, Semana 4-10 de mayo 1992, pp. 166-167.

76 S.T.C. $137 / 1988$ de 7 de julio.

77 S.T.C. 57/1990 de 26 de marzo. 
embargo, como ya hemos manifestado en páginas anteriores, el careo es un medio de prueba que, si bien puede ser subsidiario de otras que contribuye a contrastar, posee una característica esencial que consiste en precisar, de forma ineludible, la presencia judicial para su celebración. Esto es, ha de realizarse con estricto respeto al principio de inmediación, dado que resulta esencial para poder valorar las actitudes y comportamientos de las partes durante el careo.

La imprescindible inmediación que necesita la prueba de careo, conduce a afirmar que su práctica como prueba anticipada ante el juez de instrucción, con posterior lectura de lo allí acontecido en el juicio oral, priva a tal prueba de la nota de inmediación que resulta consustancial tanto a su naturaleza como a las características con que normativamente aparece configurada; una inmediación que se proyecta sobre la apreciación de las actitudes de los careados durante el acto (art. 453 L.E.Cr.). En consecuencia, estimamos que la falta de inmediación por parte del órgano que va a valorar la prueba priva a ésta de toda su virtualidad a efectos probatorios, convirtiéndola en inane.

Por lo tanto, y a modo de resumen de lo anteriormente afirmado, señalamos que la práctica de un careo durante la fase de instrucción no resulta justificada a efectos probatorios por la falta de inmediación del juzgador a quo. Tan sólo puede resultar apropiada en el caso de que la diligencia se haga necesaria, únicamente, como medio de investigación en la causa.

\section{Conclusiones}

Del estudio realizado sobre el careo y del papel que el mismo lleva a cabo en el ámbito del proceso penal se pueden deducir diversas conclusiones:

1. El careo se define como un acto consistente en la confrontación de declaraciones de imputados, de testigos o de unos y otros, con el que se pretende llegar a esclarecer algún hecho o circunstancia de interés para el proceso y sobre el cual las personas anteriormente mencionadas hubieren prestado declaraciones discordantes.

2. Del examen de sus características normativas y de la doctrina mayoritaria que se pronuncia en torno al careo, se deduce que se trata de un medio de prueba vicario, carente de autonomía e independencia al poseer como finalidad el contraste y verificabilidad de declaraciones ya prestadas con anterioridad en la causa.

3. El careo es un medio subsidiario de prueba, a practicar tan sólo a falta de otros que evidencien la existencia del delito o la culpabilidad 
de los imputados. Esta característica y la naturaleza potestativa del careo imprimen un carácter peculiar al mismo, al otorgar al juzgador una discrecionalidad en su admisión que no es revisable en casación y cuya negativa no constituye vulneración del derecho a utilizar los medios de prueba pertinentes para la defensa, consagrado en el artículo 24.2 de la Constitución.

4. La doctrina jurisprudencial mayoritaria muestra hacia el careo, como medio de prueba, una señalada reticencia que justifica en razón a dos circunstancias: su propensión a producir enfrentamientos dialécticos y violencias entre los partícipes y los escasos resultados que en la práctica se obtienen del mismo.

Se trata, por tanto, de un instrumento probatorio de utilidad discutible y cuya práctica resulta sumamente delicada para el órgano judicial que la lleva a cabo, sin olvidar que las circunstancias de enfrentamiento e incluso de violencias, al menos verbales, a que es proclive, unidas al objetivo de la Ley de Enjuiciamiento Criminal (art. 713) de «llegar a descubrir la verdad», compaginan mal con la imposibilidad de que el imputado sea obligado a declarar y con sus derechos a guardar silencio, a no declarar contra sí mismo y a no confesarse culpable.

5. La peculiaridad del careo, en cuanto a que puede llegar a enfrentar a delincuente y víctima, es muy tenido en cuenta por los tribunales a la hora de decidir sobre la pertinencia de su práctica, ya que, en muchas ocasiones: víctimas de delitos contra la libertad sexual, menores de edad, disminuidos psíquicos, puede agravar el daño sufrido por el sujeto pasivo, produciendo una auténtica victimización secundaria sin que, en tales circunstancias, se logre el equilibrio necesario entre las partes como para que las víctimas se manifiesten con libertad.

6. El valor probatorio del careo está indudablemente vinculado a la apreciación que, en conciencia, efectúa el juzgador a quo del resultado del mismo. La jurisprudencia, en razón a las características de tal medio de prueba y al fundamental papel que ha de jugar en el mismo la inmediación por estar operándose sobre un presente (actitud de las partes durante el acto), señala que su valoración está reservada, más aún si cabe que en otras pruebas, a la libre apreciación del órgano judicial. Todo ello tiene como consecuencia la carencia de valor probatorio, $y$ por tanto de utilidad a estos efectos, de la prueba anticipada practicada ante el Juzgado instructor.

7. La actitud mostrada por las partes en el careo es un parámetro a efectos valorativos de la prueba que, además de contar con apoyo normativo, se utiliza insistentemente por la doctrina jurisprudencial. Este elemento, debidamente observado y analizado por un juzgador formado en Psicología judicial, puede ser decisivo para llevar a cabo la tarea de 
valoración probatoria y, en definitiva, para adoptar la correspondiente resolución judicial.

8. El careo no es un medio de prueba más, sino que sus características plantean diversas exigencias a los órganos judiciales:

1. a Un atento estudio de la causa, tanto del hecho cometido como de las características y circunstancias de las partes intervinientes en el mismo y de sus testigos, con el fin de valorar adecuadamente la pertinencia y oportunidad de acceder a la práctica de un careo o incluso de acordarlo de oficio. Por otro lado, la naturaleza subsidiaria de tal prueba exige al juzgador ponderar la virtualidad de las demás pruebas practicadas y la necesidad o intrascendencia del careo para dictar la correspondiente sentencia.

2. ${ }^{a}$ Acordada su práctica, el careo exige del juez una exquisita atención hacia el desenvolvimiento del mismo, de forma que, evitando actitudes de violencia o presión entre las partes, lo conduzca hacia lo que debe ser la finalidad del mismo: contribuir a esclarecer la existencia y circunstancias del hecho delictivo y la participación y culpabilidad de los encausados.

3. ${ }^{\text { }}$ La delicada tarea del juez, tanto a la hora de decidir sobre la realización del careo, como de dirigir su desarrollo, requiere de una formación en materias tales como Psicología judicial, técnicas confrontativas, Victimología y Criminología, entre otras, a fin de adoptar su decisión con el mayor conocimiento posible de los elementos y circunstancias relacionados con el careo y conducir el mismo con la menor incidencia negativa de carácter emocional en sus partícipes, sobre todo en las víctimas del delito.

\section{Bibliografía}

Albacar, J.L., «El principio de libre apreciación de la prueba en la doctrina del Tribunal Constitucional», en La Ley, 1981-4, pp. 1.085-1.092.

Almagro Nosete, J., Constitución y proceso, Bosch, Barcelona, 1984.

Almagro Nosete, J. y otros autores, Derecho Procesal, Tomo II «Proceso Penal», Tirant lo Blanch, Valencia, 1992.

Arroyo de las Heras, A. y Muñoz Cuesta, J., Ley de Enjuiciamiento Criminal, Aranzadi, Pamplona, 1993.

Asensio Mellado, J.M., «La prueba. Garantías constitucionales derivadas del artículo 24.2», en Poder Judicial, 2. ${ }^{a}$ época, n. ${ }^{\circ}$ 4, diciembre 1986, pp. 33-47.

CÓRDOBA RoDA, J., «El derecho a la presunción de inocencia y la apreciación judicial de la prueba», en Revista Jurídica de Catalunya, n. ${ }^{\circ}$ 4, 1982, pp. 817-826.

DíAZ CABIALE, J.A., «La admisión y práctica de la prueba en el proceso penal», en Cuadernos del Consejo General del Poder Judicial, 1991. 
Fenech, N., El Proceso Penal, Agesa, Madrid, 1982.

FERnÁndez EnTRALGO, J., «Presunción de inocencia, apreciación de la prueba y motivación de la sentencia», en Revista General de Derecho, n. ${ }^{\text {s }}$ 493-494, octubre-noviembre 1985, pp. 3.107-3.158.

FERnÁNDEZ EnTRALGO, J., «Prueba ilegítimamente obtenida», en La Ley, 1990-1, pp. 1.180-1.192.

GARCÍA GARCÍA, J., «La fase de instrucción en diligencias de carácter criminal», en La Ley, 1994-2, pp. 1.052-1.060.

Gimeno Sendra, V. y otros autores, «Derecho Procesal», Tomo II, Proceso Penal, Tirant lo Blanch, Valencia, 1992.

GisBeRT GisBerT, A., «La práctica de diligencias de prueba acordada de oficio en el juicio oral», en Revista General de Derecho, n. ${ }^{\circ}$ 573, junio 1992, pp. 5.1415.143 .

Gómez de Liaño, F., El Proceso Penal, Forum, Oviedo, 1989.

Gómez Orbaneja, E. y Herce Quemada, V., Derecho Procesal Penal, Agesa, Madrid, 1987.

Gui Mori, T., «Filosofía constitucional de la prueba», en La Ley, 1991-2, pp. 1.149-1.156.

JiMÉnEZ AsEnjo, E. y otros autores (Mascarenas, C.E., Dir.), Nueva Enciclopedia Jurídica, Tomo III, Seix, Barcelona, 1951.

Juanes Peces, A., «Hacia un nuevo enfoque de la presunción de inocencia. La imparcialidad del juez como núcleo básico del Derecho a la presunción de inocencia», en La Ley, 1996-1, pp. 1.755-1.759.

Montero Aroca, J. y otros autores, «Derecho Jurisdiccional III», Proceso Penal, Bosch, Barcelona, 1994.

Moreno Catena, V. y otros, Derecho Procesal Penal, Colex, Madrid, 1996.

Navarro PÉrez, J.L., Ley de Enjuiciamiento Criminal, Comares, Granada, 1990.

Prieto-Castro, L. y Gutiérrez de Cabiedes, E., Derecho Procesal Penal, Tecnos, Madrid, 1989.

Queralt JimÉnEZ, J.J., «Instrucción y Derechos Fundamentales. A propósito del Procedimiento Abreviado», Actualidad Penal, n. ${ }^{\circ}$ 40, 30 octubre-5 noviembre 1995, pp. 767-773.

Ramos MÉndez, F., El proceso penal. Segunda lectura constitucional, Bosch, Barcelona, 1991.

Romero Coloma, A.M., «Problemática de la prueba testimonial en el proceso penal español», en Actualidad Penal, n. ${ }^{\circ} 22,1990$, pp. 229-240.

RuIZ-JARABO COLOMER, D., «El derecho del inculpado a no declarar y a no decir la verdad», en Poder Judicial, n. ${ }^{\circ}$ 6, marzo, 1983, pp. 27-30.

RuIZ VADILlO, E., «La actividad probatoria en el proceso penal español», en $L a$ prueba en el proceso penal, Centro de Estudios Judiciales, Cursos, n. ${ }^{\circ}$ 12, Ministerio de Justicia, Madrid, 1993.

Ruiz Vadillo, E., Estudios de Derecho Procesal Penal, Comares, Granada, 1995.

SAAVEDRA RuIZ, J., «La iniciativa del Tribunal en el acto del Juicio Oral», en Cuadernos de Derecho Judicial. Cuestiones de Derecho Judicial, Consejo General del Poder Judicial, Madrid, 1994, pp. 12-50. 
Stampa Braun, J.M., «Los derechos de la defensa y los límites de su ejercicio», en Poder Judicial, n. ${ }^{\circ}$ 14, marzo 1985, pp. 23-26.

TAFUR LÓPEZ DE LEMUS, J., «Valor probatorio de las declaraciones de testigo no presente en el acto del juicio oral», en Actualidad Penal, n. ${ }^{\circ}$ 18, Semana 4-10 de mayo 1992, pp. 161-170.

TOMÁs y VALIENTE, F., «In dubio pro reo, libre apreciación de la prueba y presunción de inocencia», en Revista Española de Derecho Constitucional, n. ${ }^{\circ}$ 20, mayo-agosto 1987 , pp. 9-34.

URquía Gómez, F. y otros autores, Ley de Enjuiciamiento Criminal. Comentarios y Jurisprudencia, Edersa, Madrid, 1990.

VALle MuÑz, J.M., Ley de Enjuiciamiento Criminal y otras normas procesales, Aranzadi, Pamplona, 1995.

VÁzquez Sotelo, J.L., Presunción de inocencia del imputado e íntima convicción del Tribunal, Bosch, Barcelona, 1984.

Vegas Torres, J., «Presunción de inocencia y prueba en el proceso penal», La Ley, Madrid, 1993. 